\title{
Preparation of Human Inner Ear Structures for High Resolution Imaging Studies
}

\author{
Marjan Mirsalehi, ${ }^{1,2}$ Saleh Mohebbi, ${ }^{1,3}$ Sedigheh Ebrahimpoor, ${ }^{1,4,}{ }^{*}$ Mark Philip Kuhnel, ${ }^{5}$ Thomas \\ Lenarz, ${ }^{1}$ and Omid Majdani ${ }^{1}$ \\ ${ }^{1}$ Department of Otolaryngology, Hannover Medical School, Hannover, Germany \\ ${ }^{2}$ Brain and Spinal Cord Injury Research Center, Neuroscience Institute, Tehran University of Medical Sciences, Tehran, Iran \\ ${ }^{3}$ Skull Base Research Center, Rasool Akram Hospital, Iran University of Medical Sciences, Tehran, Iran \\ ${ }^{4}$ ENT and Head and Neck Research Center and Department, Hazrat Rasool Akram Hospital, Iran University of Medical Sciences, Tehran, Iran \\ ${ }^{5}$ Institute of Pathology, Hannover Medical School, Hannover, Germany \\ "Corresponding author: Sedigheh Ebrahimpoor, ENT Department, Rasool Akram Hospital, Niayesh St., Sattarkhan Ave, Tehran, Iran. Tel: +98- 9128408436, Fax: +98- 2166511011, \\ E-mail: bio.ebrahimpoor@gmail.com
}

Received 2017 June 03; Accepted 2017 July 22.

\begin{abstract}
Background: Introduction of the novel imaging modalities such as optical coherence tomography and scanning laser optical tomography allow the morphological and functional evaluation of the intracochlear structures up to the histological details. The prerequisite of these modalities is the preparation of the membranous labyrinth by removing the dense otic capsule to enhance the optical penetration depth. In the present study, a combination of the chemical decalcification and bone drilling method was explained for the preparation of the human inner ear structures for further studies.

Methods: In this study, nine human temporal bones were used and trimmed in cubes containing middle and inner ear structures. The samples were immersed in 5\% nitric acid, 20\% EDTA, and 10\% EDTA solutions, respectively. The samples were brought out and rinsed every 90 minutes, and mechanical removal of the softened bone was performed with surgical drill system until the complete decalcification of the samples was confirmed by X-ray imaging. The prepared samples were evaluated by microcomputed tomography imaging for anatomical distortions caused by the preparation process.

Results: Complete decalcification and preparation of the samples were obtained in average of $10.5 \pm 0.5$ hours. No obvious morphological changes were observed in microcomputed tomography images, except for fracture of the remnant bony shell at the apex of cochlea in one sample.

Conclusions: The combination of the chemical decalcification and mechanical removal of the softened bone can accelerate the sample preparation for high resolution imaging studies without significant morphological changes.
\end{abstract}

Keywords: Temporal Bone, Inner Ear Anatomy, Decalcification, Cochlea, High Resolution Imaging

\section{Background}

Evaluating the intracochlear anatomy is essential in understanding hearing loss physiopathology and improving hearing rehabilitations. Although histopathologic preparation studies that are commonly used have the appropriate resolution, these procedures require several time consuming preparations such as chemical fixation, dissection, decalcification, embedment, and sectioning. On the other hand, some temporal bone electrode insertion studies that evaluated the intracochlear violation after implantation with histopathologic preparation reported the increased rate of intracochlear trauma compared to clinical results of the same electrode, which raised the possibility of preparation artifacts in temporal bone studies $(1,2)$.

The clinically available imaging modalities such as computed tomography (CT) and magnetic resonance imaging (MRI) did not present the proper resolution for evaluation of the intracochlear soft tissue structures (3). The experimental imaging modalities such as microcomputed tomography have the appropriate resolution for high density structures of the petrous bone, but visualization of the intracochlear soft tissue structures requires minimizing the bone density surrounding these structures by decalcification and/or mechanical removal (4). Improvements in experimental imaging technologies have introduced novel modalities such as optical coherence tomography $(\mathrm{OCT})(5,6)$ and scanning laser optical tomography (SLOT) (7) for inner ear structural visualization. Due to the limited penetration of the optical or laser beams applied in these modalities, preparation of the temporal bones by decreasing the density and thickness of the otic capsule is a prerequisite.

Ethylenediaminetetraacetic acid (EDTA) is a neutral 
fluid containing chelating agent used for decalcification and preserves the structure and integrity of the specimen well, but the prolonged demineralization period can restrict its use (8-10). Organic and inorganic acids such as formic acid and nitric acid are also used for bone decalcification. Compared to EDTA, the acids can accelerate the procedure, but the preservation of the microstructures and tissue stainability may decrease using these mediums (10).

In the current study, a combination of the chemical decalcification and mechanical removal of the otic capsule was represented to prepare the membranous labyrinth for new imaging modalities.

\section{Methods}

\subsection{Temporal Bone Preparation}

In this study, 9 fresh frozen human temporal bones were used, which were acquired from the donated bodies of the affiliated anatomy department. Due to the anonymous use of the temporal bones, ethical approval was not required. The specimens were trimmed in cuboidal shape containing the middle and inner ear to remove the excessive tissue. The margins of cutting were limited to the tympanic membrane laterally, the internal auditory canal orifice at medial, and inferiorly to the styloid process (Figure 1A). Trimming was extended by grossly removing the excessive bony and soft tissues (Figure 1B). The final sample weights were between 13 and 14 grams. After trimming, the ossicles were removed, but the stapes footplate remained intact. The superior semicircular canal dome was opened to facilitate the entrance of the solution into inner ear. To ensure the preservation of the structures after cutting and to rule out the anatomical anomaly, the samples were scanned with digital volume tomography (Xoran xCAT, Medical Diagnostic Systems Vertriebs GmbH, Neidenstein, Germany), with the following settings: X-ray tube voltage of $120 \mathrm{kV}$ with a current of $2.5 \mathrm{~mA}$, and voxel size of $300 \mu \mathrm{m}$. The samples were stored in $4 \%$ paraformaldehyde at $4{ }^{\circ} \mathrm{C}$ for 12 hours for tissue fixation.

\subsection{Decalcification and Bone Removal of the Labyrinth}

The fixed temporal bone samples were immersed separately in $5 \%$ nitric acid (NA) on an orbital shaker (with speed of 80 times/minute), at room temperature $\left(20^{\circ} \mathrm{C}\right)$. After 90 minutes, the samples were brought out and rinsed by tap water. The softened demineralized bony parts of the sample were removed with surgical drill system (EVOlution, NSK America Corp, IL, USA) by an experienced otologist. Bone removal at this stage was performed by $3 \mathrm{~mm}$ burr drill bits and continued until the softened excessive bony structures were totally removed and not exceed to the dense parts. Afterwards, the bone dusts were removed by rinsing the samples in water and the previous steps were repeated iteratively until the specimen reached to about $6 \mathrm{~g}$ weight and the surgeon felt reaching the fragile structures of the inner ear (Figure 1C). At this stage, the NA solution was replaced with $20 \%$ EDTA ( $\mathrm{pH}: 7.4$ ) and placed on the orbital shaker for 90 minutes, and then the softened parts were drilled after replacing the drill bit with diamond drill. These procedures were repeated until the sample's weight reached to $3 \mathrm{~g}$ (Figure 1D). At this stage, $20 \%$ EDTA solution was replaced by $10 \%$ EDTA (pH: 7.4). The immersion and drilling stages were repeated until the endpoint of demineralization and bone removal was confirmed by X-ray examination (Figure $1 \mathrm{E}$ and F).

\subsection{Scanning with Microcomputed Tomography}

When it was confirmed that bone removal was sufficient, the samples were rinsed by water and placed in containers, which had phosphate buffered saline (PBS). Microcomputed scans were acquired, using the $\mu \mathrm{CT} 100$ scanner (SCANCO Medical AG, Bruttisellen, Switzerland). The following settings were used: the X-ray source: $70 \mathrm{kVp}, 60$ $\mu \mathrm{A}$, scanning time of 1 to 2 hours, and resolution of 4.5 $\mu \mathrm{m} /$ voxel. To assess the morphological changes, scrolling through the images via Image (US National Institutes of Health, Bethesda, Maryland, USA) was performed, and every $10^{\text {th }}$ image was evaluated for any bony or soft tissue disintegration such as bony fractures and soft tissue anatomy distortions.

\section{Results}

Complete decalcification and sample preparation was achieved in average of $10.5 \pm 0.5$ hours. The final weights of the samples reached to mean $405 \pm 10 \mathrm{mg}$. (Table 1 )

The mean number of images obtained from the microcomputed tomography was $1697 \pm 76$. Each 10 th image was evaluated for morphological changes. The cochlea was covered with a smooth thin shell of the bone in all samples. This bony remnant was intact in all the samples, except for TB-8, in which the fracture of the bony cover with displacement was evident at the apex of the cochlea (Figure 2B). The structure of stria vascularis remained well defined and separation of the stria from the bony lateral wall was not observed. The basilar membrane preserved its continuity in all images. No unusual artifact was visible. Evaluation of the Reissner's membrane was not possible due to the limitation of the imaging modality (Figure 2A). 

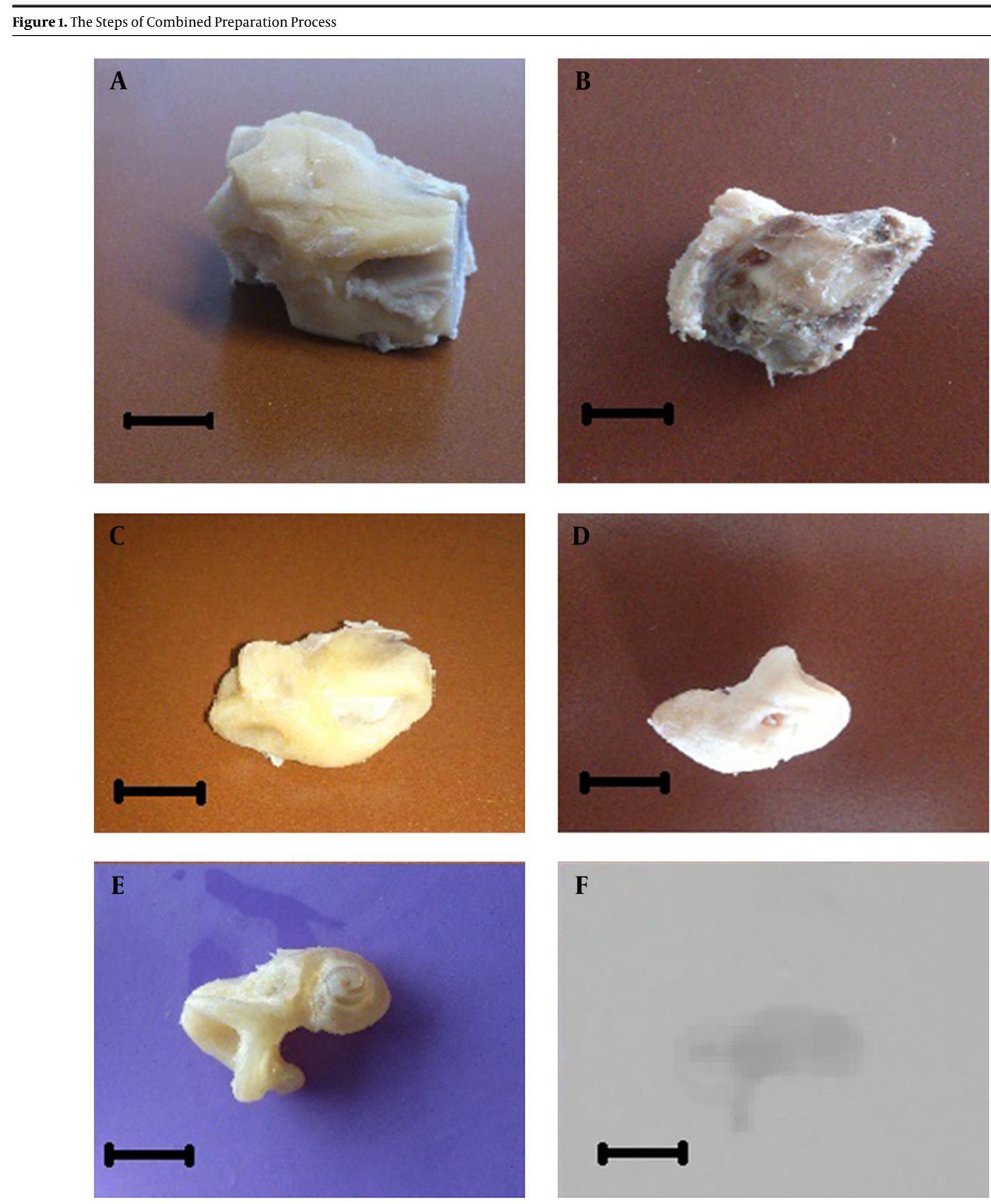

A, The temporal bone was cut in cube form; B, Excessive bony and soft tissues were removed grossly (sample weight: 13 - $14 \mathrm{~g}$ ); C, Intermittent decalcification with $5 \%$ nitric acid and drilling were performed (down to $6 \mathrm{~g}$ sample); D, The decalcification with 20\% EDTA and drilling were continued (down to $3 \mathrm{~g}$ ); E, The decalcified labyrinth; F, Complete decalcification of the sample was confirmed by X-ray imaging. The scale bars represent 1 centimeter.

\section{Discussion}

The novel improvements in imaging technologies resulted in the introduction of experimental imaging modalities to evaluate the intracochlear microanatomy such as OCT and SLOT $(7,11-14)$. These high resolution 

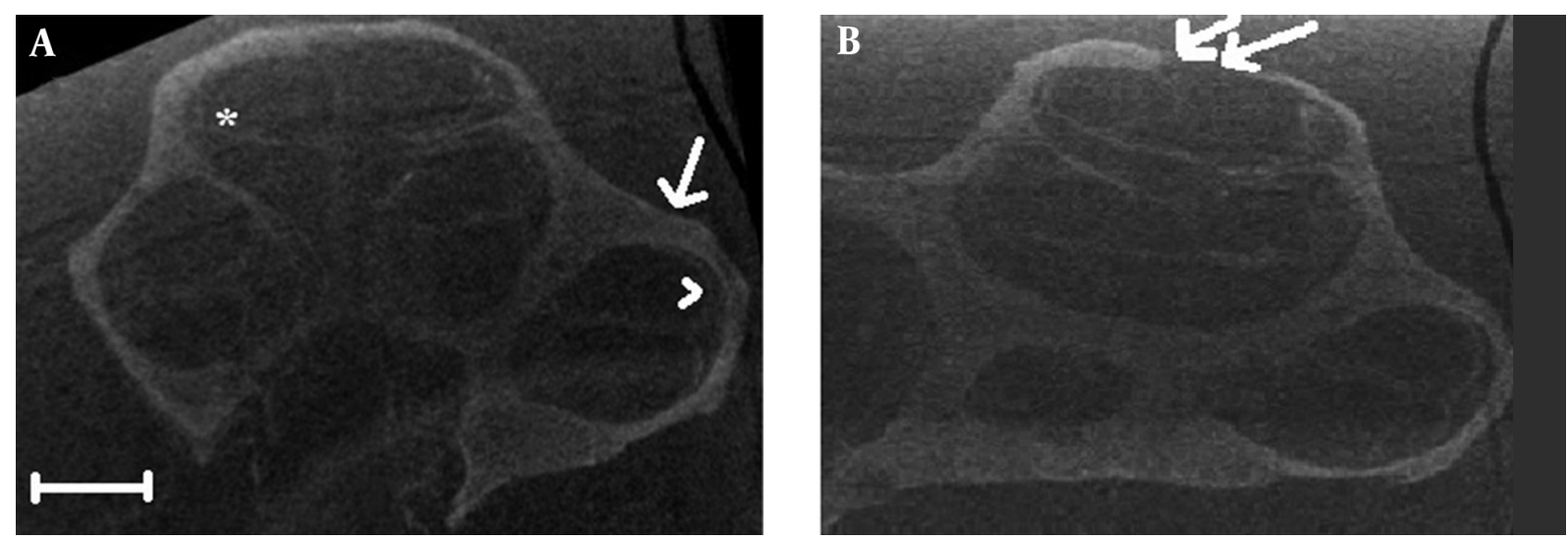

A, No discernible morphological changes were evident in bony and soft tissue structures; arrow, residual bony labyrinth, arrow head, stria vascularis, asterisk: basilar membrane; B, Integrity of the bony remnant was not preserved at apex of the cochlea in sample TB-8 (double arrow). The scale bar represents 1 millimeter.

Table 1. Summary of the Results of Sample Preparation

\begin{tabular}{cccc}
\hline Sample & Final Weight, mg & $\begin{array}{c}\text { Time Required } \\
\text { for Preparation, } \\
\text { hr }\end{array}$ & $\begin{array}{c}\text { Trauma in } \\
\text { micro-CT } \\
\text { Evaluation }\end{array}$ \\
\hline TB-1 & 400 & 10.0 & None \\
\hline TB-2 & 420 & 10.7 & None \\
\hline TB-3 & 390 & 11.0 & None \\
\hline TB-4 & 405 & 11.3 & None \\
\hline TB-5 & 402 & 10.0 & None \\
\hline TB-6 & 395 & 10.5 & None \\
\hline TB-7 & 415 & 11.0 & None \\
\hline TB-8 & 417 & 10.5 & $\begin{array}{c}\text { Fracture of the } \\
\text { surrounding bone } \\
\end{array}$ \\
\hline TB-9 & 400 & 10.0 & at apex \\
\hline
\end{tabular}

modalities are nondestructive and facilitate near real time evaluation of the structures. The limiting factor of these techniques is optical penetration depth. Because of the position of the cochlea in human temporal bone, which is surrounded by dense otic capsule, these studies are mostly limited to animal experiments. Decreasing the bony depth of osseous labyrinth is necessary to prepare the human cochlea for these studies. Because of the complex anatomy and curvature of the cochlea, bone removal, using only surgical drilling in unprepared specimens, may lead to fractures and trauma to the intracochlear structures (15). Therefore, this combined preparation method was introduced in the current study to provide a proper sample with chemical decalcification and mechanical removal for mi- croanatomy studies.

Decalcification with strong mineral acids such as nitric acids can accelerate demineralization. Callis et al. evaluated the impact of various decalcifying solutions on weight-matched sections of the canine humeri. The samples were immersed in 10\% nitric acid and demineralized in 7 days. This period was as long as 16 to 40 days in samples immersed in EDTA, depending on the $\mathrm{pH}$ of the solution (10). Prasad et al. compared the decalcification time of the fixed size segments of the rat mandibular bone with different agents. The mean period of complete decalcification was $1.7 \pm 0.3,2.3 \pm 0.4$ and $17.9 \pm 2.0$ days for $10 \%$ formal nitric acid, $8 \%$ formal nitric acid, and EDTA solutions, respectively (8). The limiting factor of nitric acid is that overexposure to this solution may cause morphologic destruction of the sample $(10,16)$.

EDTA is an excellent decalcifying solution for preservation of tissue morphology. Prasad et al. compared the histology of the mandibular segments of the rats decalcified with different agents, and demonstrated that samples, which were decalcified in EDTA represented better tissue integrity, stainability, and less friable than samples demineralized in nitric acid (8). The limitation of EDTA is that demineralization with this agent is too slow and timeconsuming.

The standard preparation method of the temporal bone, which is wildly used, was introduced by Schuknecht. In this method, complete decalcification of the temporal bone with EDTA took almost 9 months (17). Arnold et al. declared that a period of more than 6 to 12 weeks immersion in EDTA is necessary for temporal bone decalcification (9). Cunningham et al. applied microwave decalcification accelerated demineralization process in human temporal 
bones. They immersed the temporal bone plugs in 0.35 mol/L EDTA, and placed it in a laboratory microwave oven. Complete decalcification occurred in average of 5 weeks (18). Keithley et al. accelerated the microwave decalcification of human temporal bones, soaked in EDTA, with cutting the samples in cuboidal shapes with $1.5-2 \mathrm{~cm} / \mathrm{side}$, containing the inner and middle ear structures. By decreasing the size of the samples, they reached the decalcified temporal bones in 190 - 400 hours (19). Johnson et al. evaluated the soft tissue anatomy of the human temporal bones with thin-sheet laser imaging microscopy (TSLIM) optical sectioning. They prepared one temporal bone for TSLIM process and compared the detailed anatomy images obtained by this method with traditional celloidin embedded histology images. For sample preparation, complete decalcification in 0.27 mol EDTA followed by excessive tissue trimming was performed in both methods. The samples decalcified in 298 and 458 days, depending on the sample size (20). In the present study, the samples were cut in $3 \times 3 \mathrm{~cm}$ cubes to decrease the time of decalcification. At the early stages of the process, nitric acid solution was used for gross removal of the surrounding softened tissues and reduction of the preparation time. For fine bone removal, the decalcifying agent was replaced with EDTA to avoid induced artifacts reported by nitric acid overexposure. On the other hand, friability of the samples is lower while using EDTA (8), which is necessary for bone removal with drilling. In the current study, the preparation of the cochlea with decalcification and bone removal was finished in average of $10.5 \pm 0.5$ hours, which is less than the decalcification periods reported above.

The rate of decalcification is affected by environmental factors such as $\mathrm{pH}$, temperature, and agitation. Collis et al. evaluated the effect of $\mathrm{pH}$ on decalcification time. The decalcification process was performed on canine humeral head with 10\% EDTA and different pHs of 3.2, 7.0, and 10.3. Decalcification did not occur in samples with acidic $\mathrm{pH}$. The samples with neutral $\mathrm{pH}$ were decalcified in 40 days, and samples with alkaline $\mathrm{pH}$ in 16 days. They demonstrated that increasing $\mathrm{pH}$ can accelerate the decalcification process, but alkaline $\mathrm{pH}$ could associate with protein denaturation and was not recommended (10). The neutral $\mathrm{pH}$ of 7.4 was used in the present study to prevent tissue distortion. Rising the temperature can accelerate the decalcification speed (21), but there are some concerns about the risk of overheating; and temperature above $45^{\circ} \mathrm{C}$ is not recommend $(10,22)$. Mechanical agitation was demonstrated to accelerate decalcification by replacing the calcium saturated solutions surrounding the samples with fresh mediums $(10,21,22)$, and slow stirring agitation represented better histologic results (22). In the current study, the procedure was performed at room temperature due to lack of instruments that prevent overheating. Orbital shaker was used for mechanical agitation.

Cunningham et al. decalcified human temporal bones using laboratory microwave oven. The cochlea was softened and semi-lucent after 2 weeks, and complete decalcified cochlea was achieved in 5 weeks (18). Madden et al. combined decalcification in microwave oven by intermittent tissue removal for primate's cochleae. They dissected the Japanese macaque's cochlea, immersed it in EDTA, placed the sample in laboratory microwave oven, and the decalcified tissue was removed by scalpel every 90 minutes. Complete decalcified cochlea was achieved in 2 working days, with preserved cochlear ultrastructures proved by electron microscopy evaluation (23). In the present study, mechanical removal of the softened tissues with drilling was used at 90 minutes intervals of decalcification to accelerate tissue preparation. Drilling removes the calcium bounded with chelating agent, and fresh unbounded tissue is brought to the surface. Drilling limited to the softened tissue causes a smooth surface with the same depth of remained tissue in all surfaces (24). Because of the complex anatomy and curvatures of the cochlea, drilling should be performed by an experienced otologist who is familiar with the inner ear anatomy.

In conclusion, the preparation method introduced in the current study can accelerate the cochlear preparation by combination of chemical decalcification and mechanical drilling, which is necessary for novel imaging technologies. The anatomy of intracochlear structures is preserved with this combined method.

\section{Acknowledgments}

The authors would like to thank Peter Erfurt, Institute for Audio-Neuro-Technology, Hannover Medical School, for his support in specimen and medium preparation. This work has been supported by German research foundation (DFG, cluster of excellence Hearing4all, MA 4038/3-1 and MA 4038/6-1).

\section{Footnote}

Conflicts of Interest: The authors declare that they have no conflict of interest.

\section{References}

1. De Seta D, Torres R, Russo FY, Ferrary E, Kazmitcheff G, Heymann $D$, et al. Damage to inner ear structure during cochlear implantation: Correlation between insertion force and radio-histological findings in temporal bone specimens. Hear Res. 2017;344:90-7. doi: 10.1016/j.heares.2016.11.002. [PubMed: 27825860]. 
2. Mirsalehi M, Rau TS, Harbach L, Hugl S, Mohebbi S, Lenarz T, et al. Insertion forces and intracochlear trauma in temporal bone specimens implanted with a straight atraumatic electrode array. Eur Arch Otorhinolaryngol. 2017;274(5):2131-40. doi:10.1007/s00405-017-4485-Z. [PubMed: 28238160].

3. Rau TS, Wurfel W, Lenarz T, Majdani O. Three-dimensional histological specimen preparation for accurate imaging and spatial reconstruction of the middle and inner ear. Int J Comput Assist Radiol Surg. 2013;8(4):481-509. doi: 10.1007/s11548-013-0825-7. [PubMed: 23633112].

4. Decraemer WF, Dirckx JJ, Funnell WR. Three-dimensional modelling of the middle-ear ossicular chain using a commercial high-resolution X-ray CT scanner. J Assoc Res Otolaryngol. 2003;4(2):250-63. doi: 10.1007/s10162-002-3030-x. [PubMed: 12943376].

5. Pau HW, Lankenau E, Just T, Behrend D, Huttmann G. Optical coherence tomography as an orientation guide in cochlear implant surgery? Acta Otolaryngol. 2007;127(9):907-13. doi: 10.1080/00016480601089408. [PubMed: 17712667].

6. Mohebbi S, Mirsalehi M, Kahrs LA, Ortmaier T, Lenarz T, Majdani O. Experimental Visualization of Labyrinthine Structure with Optical Coherence Tomography. Iran J Otorhinolaryngol. 2017;29(90):5-9. [PubMed: 28229056].

7. Nolte L, Tinne N, Schulze J, Heinemann D, Antonopoulos GC, Meyer $\mathrm{H}$, et al. Scanning laser optical tomography for in toto imaging of the murine cochlea. PLoS One. 2017;12(4):e0175431. doi: 10.1371/journal.pone.0175431. [PubMed: 28388662].

8. Prasad P, Donoghue M. A comparative study of various decalcification techniques. Indian J Dent Res. 2013;24(3):302-8. doi: 10.4103/09709290.117991. [PubMed: 24025875].

9. Arnold W. Immunohistochemical investigation of the human inner ear. Limitations and prospects. Acta Otolaryngol. 1988;105(5-6):392-7. doi: 10.3109/00016488809119491. [PubMed: 3041735].

10. Callis G, Sterchi D. Decalcification of bone: Literature review and practical study of various decalcifying agents. Methods, and their effects on bone histology. J Histotechnol. 2013;21(1):49-58. doi: 10.1179/his.1998.21.1.49.

11. Wong BJ, Zhao Y, Yamaguchi M, Nassif N, Chen Z, De Boer JF. Imaging the internal structure of the rat cochlea using optical coherence tomography at 0.827 microm and 1.3 microm. Otolaryngol Head Neck Surg. 2004;130(3):334-8. doi: 10.1016/j.otohns.2003.11.007. [PubMed: 15054375].

12. Gao SS, Xia A, Yuan T, Raphael PD, Shelton RL, Applegate BE, et al. Quantitative imaging of cochlear soft tissues in wild-type and hearingimpaired transgenic mice by spectral domain optical coherence tomography. Opt Express. 2011;19(16):15415-28. doi: 10.1364/OE.19.015415.
[PubMed: 21934905]

13. Tona Y, Sakamoto T, Nakagawa T, Adachi T, Taniguchi M, Torii $\mathrm{H}$, et al. In vivo imaging of mouse cochlea by optical coherence tomography. Otol Neurotol. 2014;35(2):e84-9. doi: 10.1097/MAO.0000000000000252. [PubMed: 24448302].

14. Ramamoorthy S, Zhang Y, Petrie T, Fridberger A, Ren T, Wang R, et al. Minimally invasive surgical method to detect sound processing in the cochlear apex by optical coherence tomography. J Biomed Opt. 2016;21(2):25003. doi: 10.1117/1.JBO.21.2.025003. [PubMed: 26836207].

15. Michaels L, Wells M, Frohlich A. A new technique for the study of temporal bone pathology. Clin Otolaryngol Allied Sci. 1983;8(2):77-85. [PubMed: 6342874].

16. Mawhinney WH, Richardson E, Malcolm AJ. Control of rapid nitric acid decalcification. J Clin Pathol. 1984;37(12):1409-13. doi: 10.1136/jcp.37.12.1409. [PubMed: 6096405].

17. Schuknecht $\mathrm{H}$. Temporal bone removal at autopsy. Preparation and uses. Arch Otolaryngol. 1968;87(2):129-37. doi: 10.1001/archotol.1968.00760060131007. [PubMed: 4865202].

18. Cunningham C3, Schulte BA, Bianchi LM, Weber PC, Schmiedt BN. Microwave decalcification of human temporal bones. Laryngoscope. 2001;111(2):278-82. doi: 10.1097/00005537-200102000-00017. [PubMed: 11210875].

19. Keithley EM, Truong T, Chandronait B, Billings PB. Immunohistochemistry and microwave decalcification of human temporal bones. Hear Res. 2000;148(1-2):192-6. doi: 10.1016/S0378-5955(00)00153-2. [PubMed: 10978836].

20. Johnson SB, Cureoglu S, O'Malley JT, Santi PA. Comparison of traditional histology and TSLIM optical sectioning of human temporal bones. Otol Neurotol. 2014;35(7):1145-9. doi 10.1097/MAO.0000000000000416. [PubMed: 24914787].

21. Verdenius HH, Alma L. A quantitative study of decalcification methods in histology.J Clin Pathol. 1958;11(3):229-36. doi:10.1136/jcp.11.3.229. [PubMed: 13539226].

22. Kapila SN, Natarajan S, Boaz K, Pandya JA, Yinti SR. Driving the Mineral out Faster: Simple Modifications of the Decalcification Technique. $J$ Clin Diagn Res. 2015;9(9):ZC93-7. doi: 10.7860/JCDR/2015/14641.6569. [PubMed: 26501022].

23. Madden VJ, Henson MM. Rapid decalcification of temporal bones with preservation of ultrastructure. Hear Res. 1997;111(1-2):76-84. doi: 10.1016/S0378-5955(97)00107-X. [PubMed: 9307313].

24. Mohebbi S, Diaz JD, Kühnel MP, Durisin M, Rau TS, Mirsalehi M, et al Optical Coherence Tomography (OCT) guided inner ear decalcification, fast and safe method. Biomed Tech. 2014;59(s1). 